\title{
Beyond Altruism: A Case for Compensated Surrogate Motherhood
}

Ruth Walker and Liezl van Zyl

Abstract: Commercial surrogacy is prohibited in many countries, and we think there are good reasons why it should remain so. Arranging surrogacy according to the norms of the free market often gives rise to exploitation of the surrogate mother, a violation of her right to participate in medical decision-making, as well as practices that endanger the health and welfare of the surrogate as well as the intended child. However, we argue that these arguments against a fully commercialized, profitdriven form of surrogacy do not extend to all forms of compensated surrogacy. In particular, we argue that fairness requires that surrogates be compensated for their labor as well as the risks they undertake. We are therefore opposed to unpaid or altruistic surrogacy. In order to safeguard against the risk of exploitation and other harmful and unethical practices we argue in favor of organizing surrogacy along the norms of professions such as nursing and teaching. This would involve establishing a professional body, which will be charged with the task of regulating fees, licensing and monitoring clinics that offer surrogacy services, and screening and registering surrogates.

\section{Author Information}

Ruth Walker is a senior lecturer in Philosophy and Ethics at the University of Waikato, New Zealand. Her research interests include bioethics, professional ethics and research ethics.

Liezl van Zyl is a senior lecturer in Philosophy and Ethics at the University of Waikato, New Zealand. Her research interests include bioethics and virtue ethics. 


\section{Beyond Altruism: A Case for Compensated Surrogate Motherhood}

\section{Introduction}

In many countries, including New Zealand, Australia, the UK, Canada, and South Africa, unpaid or 'altruistic' surrogacy is not only permitted but held forward as an ideal. A 'good' surrogate mother is someone who freely gives of herself for the sake of others, while not expecting or receiving anything in return. Current legislation in these countries typically allows surrogate mothers to be reimbursed for actual expenses related to the pregnancy, such as transport costs, medical treatment, and maternity clothing. Commercial surrogacy, understood as giving or receiving 'valuable consideration' in exchange for gestational labor, is strictly prohibited.' Despite this, many surrogate mothers do receive payment 'under the table'. ii A possible explanation for this is that these supposedly 'altruistic' women are, after all, primarily motivated by a desire for money. A competing explanation is that they are motivated by a desire to help the intended parents, and that both parties believe that payment is both appropriate and deserved. Our aim in this chapter is to support the latter view.

We are not in favor of commercial surrogacy, which we think raises a number of very serious ethical concerns. However, we also think surrogate mothers ought to be compensated for their labor and the significant risks they undertake. We argue that it is not payment as such that lies at the heart of the problems with commercial surrogacy, but rather the fact that the practice is structured as a market driven commercial enterprise. Arranging surrogacy according to the norms of the free market can give rise to exploitation of the surrogate mother as well as a violation of her rights, in particular the right to participate in medical decision-making and the right to bodily integrity. Some commercial agencies engage in practices that endanger the health and welfare of surrogate mothers as well as intended children, for example, by implanting multiple embryos to increase the chances of successful implantation, performing fetal reduction surgery in the case of multiple pregnancies, and performing medically unnecessary Caesarean sections for the convenience of the intended parents. ${ }^{\text {iii }}$

Accepting the view that surrogate mothers should be compensated for their labor does not commit us to accepting a commercial model. Instead, we propose an alternative form of compensated surrogacy, which is based on the norms of professions such as nursing and teaching. It is important to note at the outset that we do not advocate that women pursue surrogacy as a career, only that surrogacy should be organized like the caring professions. In the final section we explain the structure of the professional model and how it avoids some of the objections to altruistic and commercial surrogacy. 


\section{Altruistic surrogacy}

Altruistic surrogacy is often praised as an act of supreme kindness. Women who act as surrogate mothers are said to freely and generously give of themselves, without expecting or receiving anything in return. While we certainly do not want to judge or criticize these women, we want to question whether it is acceptable for intended parents to benefit from their extraordinary kindness without giving (and indeed, without being allowed to give) something in return.

Acts of kindness should be reciprocated in some way. For example, when a friend helps out by babysitting one's children, one might express one's gratitude and appreciation by reciprocating in a way that balances her service or sacrifice. A failure to do so could well amount to taking advantage of her kindness. If, say, the friend takes care of the children every day for a year, a failure to reciprocate would most certainly amount to exploitation. Of course, not all acts of kindness have to be reciprocated in kind. One such case is when the benefactor gives something of great value but at little cost to herself (for example, saving a child from drowning in a shallow pond). Another such case is when the benefactor is significantly better off than the beneficiary (for example, where a rich philanthropist gives money to set up a shelter for homeless people). Acts of charity are praiseworthy because they tend to serve the interests of those who are in most need, thereby reducing material inequality. In both cases a sincere 'thank you' may be appropriate, with no further reciprocation required.

Altruistic surrogacy differs from these cases in important ways. First, a surrogate mother does not help others at little cost to herself. Unlike the person who rescues a child from drowning, she experiences a significant amount of pain and discomfort associated with (either in vitro or artificial) fertilization, pregnancy, and childbirth. Whatever her motivations, which are usually complex, it is only the intended parents who benefit in any significant way. Further, unlike the rich philanthropist, the surrogate mother is usually no better off, all things considered, than the intended parents. In many cases she is financially worse off than intended parents. Given these two considerations we think it would be wrong for the intended parents not to reciprocate by giving something substantial in return. If her act of kindness remains unreciprocated then it becomes one of self-sacrifice. As Badcock (1986) argues, being a party to a self-sacrificing act, where the giver has nothing to gain and possibly much to lose from the act of giving, suggests that the beneficiary's needs are more worthy than those of the benefactor. Acts of self-sacrifice enhance the position of beneficiaries to the detriment of benefactors and are to this extent exploitative. ${ }^{\text {iv }}$ 
A possible response to this objection is that women freely choose to become surrogate mothers, fully aware of the fact that they will not be compensated, and further, that they do get something in return - they feel good about what they've done. Surrogate mothers often derive an enormous amount of satisfaction from helping others form a family. For example, Richard Fischer, a New Zealand fertility expert, writes:

It is easy to see surrogacy as being a very one-sided deal with the commissioning couple being the only ones who gain significantly from it as they are ultimately delivered a child. But for most surrogates there is also much to gain from knowing their actions have ensured both the delivery of a healthy child and the joy to a couple for whom parenthood would otherwise not occur (Fischer, 2011).

Against this we would argue that merely feeling good about what you have done in carrying a baby for someone is insufficient reward, if it is a reward at all. Pleasure and satisfaction on doing a good deed are normal human responses and are not a substitute for tangible or actual rewards that are owed to the benefactor. Women choose to act as surrogate mothers because they want to help someone form a family. However, where paid surrogacy is prohibited, these women must consent to unpaid surrogacy. That is, they either have to consent to an unfair arrangement or be prevented from participating altogether. Mere reimbursement of expenses is inadequate if the benefits and harms are to be balanced out in a way that prevents exploitation. Many intended parents would like to compensate their surrogate, but are legally prohibited from doing so. In a sense, then, they are forced to take advantage of the surrogate mother's goodwill.

In practice, many intended parents do find ways to compensate their surrogate mothers. There is very little that can be done to prevent intended parents from making payments 'under the table'. ${ }^{v}$ In other cases, a very liberal interpretation of 'expenses' allows for surrogate mothers to receive substantial amounts of money. It is unlikely that these kinds of payments serve as incentives for women to act as surrogate mothers. Rather, in most instances the intended parents want to compensate their surrogate mother out of a sense of fairness or as a means of expressing their gratitude and appreciation. Intended parents risk breaking the law and may end up feeling guilty for doing what they believe is the right thing to do. They also put the courts in an impossible position where transfer of legal parentage is required. While technically the parents are in breach of the law the judge must find some way of allowing the transfer in order to protect the best interests of the child.

Despite the concerns about altruistic surrogacy, there remains serious and widespread opposition to the idea of compensating surrogate mothers. One worry is 
that paid surrogacy amounts to treating women's bodies as objects or commodities, and that it involves a form of exploitation. Another objection is that paid surrogacy is a form of baby selling. A further worry concerns the surrogate mother's motivation: the thought is that paid surrogate mothers are motivated by money rather than a genuine desire to help others, and that they will therefore be less reliable and trustworthy than women who are motivated by altruism. We examine these objections in the following section, and argue that it is not payment itself that is the problem, but the fact that commercial surrogacy, as currently practiced in places like India, Thailand, and parts of the United States, is based on a commercial or contractual model. Our focus is on commercial surrogacy in the US as it offers a model most likely to be advocated in places like the UK and Australasia.

\section{Commercial surrogacy}

In its simplest form, a commercial relationship consists of two parties who enter into an agreement to exchange a specific product or service for money. Both parties are assumed to be motivated by personal gain, and given that each has something the other wants, both have some power to negotiate an agreement that is favorable to them. Buyers can 'shop around' to find the most attractive deal and vendors are free to advertise their goods and services, to offer discounts and guarantees, and so on. The parties are free to enter an agreement, but once they have done so, their liberties are restricted in accordance with the terms specified in the contract. Each has a set of clearly defined rights and responsibilities, and neither party has the power to renege on the agreement without incurring a penalty of some kind.

The distinguishing feature of commercial surrogacy in the US is that it based on a contractual or commercial model. Both parties are assumed to be motivated by personal gain to enter an agreement, which stipulates that the surrogate mother is to bear a child for the intended (or 'commissioning') parents in exchange for a fee. The contract typically includes a detailed list of gestational services. The list provided by a prominent US agency includes baseline compensation of US\$3,000 per month, plus a number of 'variable expenses':

$\begin{array}{lc}\text { Multiple birth compensation (beginning at week 18) } & \$ 5,000 \\ \text { Experienced surrogate - additional compensation } & \$ 5,000 \\ \text { Caesarean section (if directed by a physician) } & \$ 2,500 \\ \text { Invasive procedure compensation, per occurrence } & \$ 500 \\ \text { Fetal reduction } & \$ 750 \\ \text { Labor induction due to no heartbeat or abnormalities } & \$ 2,000 \\ \text { Loss of uterus } & \$ 2,500 \\ \text { Loss of one or more tubes } & \$ 1,000 \\ \text { Ectopic pregnancy surgery } & \$ 1,000\end{array}$


(Source: ConceiveAbilities, 2016a)

The contract also contains sections that specify the rights and responsibilities of each party, as well as the penalties for breach of the agreement (as discussed below). What motivates many objections to commercial surrogacy contracts is that they put a price on a woman's body as well as her experience of pregnancy. In what follows we discuss three such objections.

\section{a. The money motive}

A frequent objection to commercial surrogacy is that it involves exploitation of vulnerable women, for whom payment acts as undue incentive and leads them to ignore their other interests. ${ }^{\text {vi }} \mathrm{A}$ related concern is that surrogate mothers who are motivated by monetary gain rather than a sincere desire to help others are less likely to be reliable or trustworthy, and more likely to put the life or health of the intended baby at risk (British Medical Association, 1996). Money is thus deemed pernicious in two ways: it allows the exploitation of vulnerable women who act against their own interests for the sake of money, and it attracts untrustworthy people prepared to provide their body parts for money.

A common response to these objections is to question the assumption that commercial surrogate mothers are primarily motivated by money. Some of the studies conducted in the US report that the most common reasons for becoming a surrogate mother are things such as empathy for childless couples, helping others experience the joy of parenthood, doing something special and thereby gaining a sense of achievement or enhancing their self-esteem. ${ }^{\text {vii }}$ Further, agencies often reassure their clients that the women they employ are financially stable and motivated by a sincere desire to help others form a family. To be accepted into the program women must agree to psychological testing, have no history of clinical mental illness or criminal activity, have a stable and responsible lifestyle, must agree to a home visit with all persons and pets residing in the home, and be financially sound. In particular, they must not seem overly motivated by the fee (ConceiveAbilities, 2016b).

A number of studies suggest that financial motivation does play a part in the decision (Laufer-Ukeles, 2013; Van den Akker, 2003). The true extent to which surrogate mothers are motivated by money is uncertain, but given that commercial agencies seek out surrogate mothers who openly state that they are not motivated by money, it is likely that women will hide any financial motivation they might have, and will pretend instead that they don't care about money at all. The fact that women who want to participate in commercial surrogacy must hide self-interested motivation to be accepted into the program, points to a significant shortcoming of the commercial model for surrogacy. In commercial transactions, both parties are expected to look out for their own interests and to negotiate a contract that is favorable to them. They 
need not concern themselves with the interests of the other party. In the case of commercial surrogacy, where one party looks out for their own interests whereas the other is expected to show that she is only interested in serving the needs of the other, the surrogate mother is put at a significant disadvantage when it comes to negotiating a fair contract. viii Women who choose to be surrogate mothers are often taking a step to improve their situation. Just as ordinary workers are not expected to hide the fact that money helps motivate them, it is unreasonable and detrimental to the surrogate mother to expect her to disguise her motivation. Money motivates all workers to some extent.

\section{b. The rights and liberties of the surrogate mother}

Apart from seeking out women with the desired physical, psychological and motivational attributes, commercial agencies try to protect the interests of their clients (the intended parents) by including a list of responsibilities in the contract. Surrogate mothers typically agree to follow a prenatal examination schedule, to submit to any medical tests or procedures as prescribed by her obstetrician, to avoid dangerous sports and hazardous activities, to avoid cigarettes, alcoholic beverages and illegal drugs, and to avoid travelling abroad after the second trimester. In our view, these restrictions can be justified on the grounds that they provide the best chance of successfully gestating the intended baby, who has its own interests in being healthy. All employment contracts constrain the liberty of the employee to some extent, and as long as the surrogate mother freely enters the agreement, these restrictions do not unduly limit her liberty.

However, commercial surrogacy contracts have a disturbing tendency to encroach on the human rights of the surrogate mother, and this can never be justified. Surrogacy contracts frequently include a requirement to waive the right to medical confidentiality and to permit the intended parents to make important decisions about the progress of the pregnancy, such as whether to have an abortion in case of fetal abnormality, or to undergo fetal reduction in case of multiples. Proponents of commercial surrogacy often try to justify these requirements on the grounds that the intended parents acquire the right to make medical decisions on behalf of the surrogate mother, or that they are paying her to gestate a child that belongs to them. However, we think they constitute a clear violation of the surrogate mother's rights to autonomy and bodily integrity. These are fundamental human rights that cannot be contracted away. If the intended parents are granted a right to make decisions on behalf of the surrogate mother, they will be using her body merely as the environment in which their child grows. This clearly amounts to objectification. It is only when the surrogate mother's basic human rights are recognized and respected that objectification is prevented. 
Women who enter a commercial surrogacy agreement typically waive their right to decide whether to terminate the pregnancy. A sample contract provided by a popular online community includes the following clause:

If the fetus(es) has been determined by any designated physician to be physically or psychologically abnormal, the decision to abort the pregnancy ... shall be the sole decision of the Genetic Father and Intended Mother... If she refuses to have an abortion, the Surrogate agrees to the termination of all expenses.... Further, the Genetic Father and Intended Mother shall not be responsible for those medical expenses incurred by the Surrogate due to unforeseen complications of which would have been avoided had an abortion occurred. Furthermore, in the event that the Surrogate refuses to proceed with a clinical abortion, all further performance required by the Genetic Father and Intended Mother under the terms of this Agreement is excused (All about surrogacy.com, 2016).

An increasing number of surrogate mothers report being pressured by intended parents to undergo termination or fetal reduction. ${ }^{i x}$ Although the surrogate mother cannot legally be forced to abide by the intended parents' wish for termination or reduction, the terms of the contract make it almost impossible, or at least very unattractive for her not to. The financial penalties are such that very few surrogate mothers are able to resist the pressure to abide by the intended parents' wishes.

One attempt to justify the abortion clause is to argue that the right to liberty includes a right to enter contractual agreements, and that prohibiting or limiting women's ability to enter such agreements would be a gross violation of their personal autonomy. In this view, by signing a contract the surrogate mother is not waiving her right to decide whether to have an abortion; rather, she is exercising this right by giving consent, in advance, to having an abortion under specific circumstances. According to this line of reasoning, consenting in advance to abortion is no different from consenting in advance to undergoing an ultrasound scan or blood test.

We think this argument is flawed. As noted above, we support a woman's right to enter into an agreement with others to act in clearly specified ways, such as undergoing prenatal screening and having regular doctor's visits. However, the right to contract does not include a right to waive one's human rights. To give up the power to make decisions about medical interventions is just such a right. While there are some things one can consent to in advance, termination of a pregnancy is not one of them. The decision to terminate a pregnancy on the grounds of fetal abnormality is extremely complex and involves many variables, including the nature of the abnormality, its likelihood and severity, the gestational age of the fetus, and the health of the pregnant woman. In order to give free and informed consent in advance the 
surrogate mother would have to be given a list of all the possible conditions in all their possible combinations and that is literally impossible. In addition, people are generally very unreliable when it comes to predicting whether they would choose to terminate a pregnancy under certain circumstances. For example, an integrative review of recent studies found that the decision to undergo an induced termination for Down Syndrome varies depending on whether participants were prospective parents recruited from the general population (between $23 \%$ and $33 \%$ say they would terminate), or women who received a positive diagnosis of Down syndrome during the prenatal period (between $89 \%$ and $97 \%$ actually chose to terminate) (Choi et al., 2012). We would argue, therefore, that neither the surrogate mother nor the intended parents can reach an informed decision in advance (that is, prior to pregnancy being established). One cannot contract out one's right to bodily integrity to anybody. We agree with the opinion expressed by the American College of Obstetricians and Gynecologists, namely that '[t]o allow a woman to contract away the right to control her own health would be to institute contractual slavery' (ACOG, 1992, pp. 139-144). ${ }^{x}$

\section{c. Objectification of the intended baby}

Another familiar objection to commercial surrogacy is that it involves treating the intended baby as an object or commodity. Some of the discomfort with the commercial model stems from the fear that, once it becomes fully embraced, we will see a market with women advertising to attract customers and threatening to withhold the 'product' if payment is not forthcoming. Intended parents would shop round for the best deal, or refuse delivery of a defective product. In the 1980s Nancy Davis expressed the worry that once commercial surrogacy becomes a widespread practice, babies will come to be viewed as no more special a purchase than, say, the purchase of a new car, and that parents' love for their children will no longer be unconditional but will depend on whether their children were 'good products' (Davis, 1988, pp. 51-77).

Supporters of commercial surrogacy try to refute this objection by pointing out that the intended parents do not pay for the baby nor for the right to become legal parents, but rather for the surrogate mother's gestational services. The intended baby is thought to belong to the intended parents from the outset, on the grounds that it was conceived using their (genetic) gametes, or gametes that were donated to them (sometimes by the surrogate mother herself). Yet, if the contractual model is being used it is almost impossible to see it in any other terms than the production of a baby to be handed over. If there are clauses in the contract that enable the parents to refuse to take the baby or allow the surrogate mother to withhold it then the baby is treated as a commodity. 
Commercial surrogacy contracts often lead intended parents to believe that they have a right, not only to a child, but to a child that meets their specifications. Contracts typically specify that the surrogate mother is to undergo certain diagnostic and screening procedures and to agree to a termination for fetal abnormality if that is what the intended parents want, and this encourages the view that intended parents should be able to refuse to take custody of child if the surrogate does not comply. Commercial surrogacy agencies in the US attempt to avoid this problem by making it clear, in the contract, that the intended parents will take custody of the resultant child regardless of whether he/she suffers from any congenital or other abnormalities or defects, and that the surrogate mother will not be held responsible for such abnormalities or defects. However, commercial contracts often add the following qualification: 'as long as the Surrogate has not breached the terms of this Agreement'. And a surrogate mother breaches the contract if, for example, she:

Acts in a manner dangerous to the well-being of the unborn Child(ren) by failing to follow the directions of her physician, using medications or drugs not prescribed by her physician, using any tobacco product, using alcohol, attempting to intentionally inflict harm to the unborn Child(ren), or acquiring a venereal disease during the pregnancy.

Knowingly provides false or misleading information to any physician or psychotherapist as specified herein (All about surrogacy.com, 2016).

It is clear that the fate of the child in this arrangement is ultimately determined by the contract between the surrogate mother and the intended parents. In this sense the child is treated as a product or commodity.

\section{The Professional Model}

Objections to commercial arrangements lead many people to reject compensated surrogacy altogether. This is a mistake. As argued in the first section, allowing only unpaid or altruistic surrogacy is not sufficient for preventing exploitation of surrogate mothers. ${ }^{x i}$ Furthermore, many of the objections to commercial surrogacy apply to altruistic surrogacy as well. ${ }^{\text {xii }}$ To avoid exploitation and objectification of women and children, we propose that surrogacy be organized according to the norms of professions such as nursing, teaching, and social work. ${ }^{\text {xiii }}$ Like other professionals, the good surrogate mother would be motivated by care or concern for her clients and a desire to do something worthwhile, and would also be compensated for her labor. Surrogacy should be paid on a fee for service basis with a professional regulatory body that oversees selection of surrogate mothers, training and ethical standards. This body would ensure fair payment, and also that the parties were fully informed of their rights and responsibilities, that consent was freely given and that constraints on the surrogate mother were legitimate. Exploitation and unreasonable demands by the 
intended parents would be precluded, thus minimizing the risk of harm. In what follows, we show how the professional model avoids the objections to commercial surrogacy that were discussed in the previous section.

\section{a. Generosity and compensation}

Consider, again, the claim that women who are motivated by a desire to help others form a family are more likely to act in the best interests of the intended baby. Even if we accept this claim it does not follow that surrogate mothers ought not to be compensated for their labor, for the simple reason that payment does not preclude generosity. ${ }^{\text {iv }}$ There are various paid roles or occupations that one can only perform well if one views the activity as worthwhile in itself, rather than as a means of making money. Consider, for example, a profession such as nursing. It seems likely that nurses who care about the welfare of their patients will do a better job than those who are simply 'in it for the money'. Yet we do not use this as a reason not to pay them (or to reimburse them for expenses only). An act of giving can be motivated by generosity even if it is done on condition of receiving something in return. ${ }^{x v}$ In the professional model, women will ideally be motivated to participate by a desire to offer worthwhile service, while nonetheless expecting to be compensated for their work as well as the risks they undertake.

In the commercial world the motto is caveat emptor (let the buyer beware). By contrast the first principle in medicine - and it transfers to the other professions - is primum non nocere (first do no harm) (Van Mook et al., 2009, e82). In the former the buyer protects herself with a detailed, enforceable contract, and both parties act in their own interests. The latter, by contrast, puts the responsibility on the professional to protect and serve the client's interests. The professional is required to be trustworthy in a way that the tradesperson, for example, is not because, typically, a great deal is at stake and clients are vulnerable.

The professional model does not view the surrogate mother as a 'womb for hire.' Rather, it emphasizes a number of ethical principles that govern the relationship between the intended parents, the surrogate mother, and the intended baby. The professions serve interests connected to fundamental human rights and human flourishing such as health, legal rights and education. The distinctive ethical dimension requires both a code of practice and that professionals have the 'values, attitudes and motives' that enable them to put the client's interests ahead of their own (Carr, 1999, pp. 33-46). Clients are vulnerable because loss of health or liberty and an inadequate education are very serious barriers to flourishing. The vulnerability of couples seeking a surrogate mother is in the same category. For them, having children is such an important constituent of their happiness that they are prepared to go to great lengths to secure it. Agreements and contracts notwithstanding, they have little control over 
the surrogate mother's conduct during the pregnancy and have to depend on her trustworthiness and generosity.

The ground of professional trustworthiness is the public pledge members of professions make to provide services and to put the clients' interests ahead of their own (Koehn, 1994). In the case of surrogacy the promise the surrogate mother makes to the parents and the implicit promise to the fetus is at the heart of the relationship. A contract, by contrast, cannot establish trust and may even undermine it by attempting to control every aspect of the relationship. Furthermore, because obligations are confined to those arising from the stipulations in the contract, a commercial surrogate mother would be free to act as she pleased should an unexpected contingency arise. In a complex situation such as surrogacy where there are three sets of interests involved (the intended parents', the fetus's, and the surrogate mother's), all of which can be affected by unforeseen or unlikely events, dependence on such a contract is potentially dangerous for the parents. A pledge of service, however, allows for the unforeseen - just as it does for every profession where interests are complex and open-ended - because contingencies can be discussed and decided upon as they arise on the basis of the trust already established.

If selection of surrogate mothers is based on the values, attitudes and motivations that enable generosity then the matter of payment ceases to be noxious. The selection of nurses, doctors and teachers for the right motives is done quite independently of considerations of payment. Generosity and remuneration are not mutually exclusive for the standard professions so there is no reason to think that they would be for surrogate mothers. Many women would like to be surrogate mothers but are prevented from doing so because they cannot afford to undertake unpaid surrogacy. Compensation would enable them to do the generous thing they are already disposed to do. That is very different from saying that they would be 'doing it for the money'. For example, Pamela Laufer-Ukeles (2013) found that while surrogate mothers might not agree to undertake pregnancy's considerable inconvenience and expense absent payment, the desire to help others is an important consideration. ${ }^{\text {xi }}$

\section{b. The rights and liberties of the surrogate mother}

Professions have regulatory bodies that oversee selection, training and ethical standards. They also protect the interests of their members to ensure that they are not exploited or forced into unethical conduct. Pressures on professionals to act in ways that are contrary to the standards of the profession can be overlooked, as can unfair contractual obligations, when the self-regulating nature of professions is being evaluated. Individual doctors, nurses and teachers cannot easily defend themselves or their profession but professional bodies can and do. The professional model requires surrogate mothers to be registered and clinics to be licensed and regulated 
through an independent body responsible for setting the fees women receive as well as the professional standards, rights and duties of all parties. Individual surrogate mothers are vulnerable to exploitation but a regulated profession would offer protection against that by setting standards of conduct as well as limitations on what parents or agencies employing women as surrogate mothers can demand of them.

To guard against the risk of objectification the professional model emphasizes the fact that the surrogate mother, as a pregnant woman, has the right to make free and informed decisions about whether to undergo invasive diagnostic tests, have an abortion or undergo fetal reduction. She is not a vessel containing a fetus but a person with the right to bodily integrity. The intended parents must respect her agency, and refrain from coercive actions. They must accept that they are entrusting the surrogate mother with the fate of the intended baby (Walker \& Van Zyl 2015, pp. 529-535).

In order to secure an environment in which the surrogate mother can freely exercise her right to bodily integrity, payment should not be tied to the delivery of a healthy infant. Although many critics of commercial surrogacy claim that it is the payment itself that is problematic we argue that the flaw lies in the way payment is managed. For example, in cases where the surrogate mother has an abortion for fetal abnormality she should still receive full payment so that she is not penalized for doing the right thing. The relationship is based on trust rather than a contract and the intended parents are not buying a baby but (committed) service. Regulated fees, insurance and the use of trust accounts would eliminate a vast tranche of the problems that currently plague contractual surrogacy arrangements. Money should not be a factor in her decision whether to have an abortion or any other decision affecting the welfare of the intended baby or the surrogate mother herself.

\section{c. Avoiding objectification of the intended baby}

In the professional model the intended parents are recognized as the legal parents from the moment the baby is born. This ensures certainty for both parties, and best serves the needs and interests of the child because the intended parents cannot abandon the baby any more than the surrogate mother can withhold it from them. More importantly, it allows us to avoid the objection that commercial surrogacy involves treating the baby as an object in so far as the contract allows the intended parents to refuse to accept custody if the surrogate breaches the contract in some way.

Certainty for the intended parents by way of legal parentage from birth provides certainty for the intended baby. Looking at surrogacy through the UN Convention on the Rights of the Child (1990), Gerber and O'Byrne (2015, pp. 81-112) identify the child's rights to an identity, name, nationality and to know and be cared for by its parents as central to surrogacy. The professional model provides for all of these from 
birth, without the need for a transfer of parentage or any dispute about who the child's parents are. If the intended parents are the parents unconditionally then the commodification objection loses its force. The baby is not a product to be exchanged but a person who cannot become the subject of a dispute.

\section{Conclusion}

In conclusion, then, we propose a professional model in which surrogate mothers are motivated by a desire to do something worthwhile and are compensated for their labor. It is widely accepted that the work done by members of other caring professions - such as taking care of the sick and vulnerable - is in some sense priceless, but people still expect to be compensated for their labor. To guard against exploitation of surrogate mothers and other harmful and unethical practices we favor the creation of a professional body that would have the task of screening and registering surrogate mothers, regulating fees, and licensing and monitoring clinics that offer surrogacy services. Licensed clinics would be required to use registered surrogate mothers and provide all support services that the parties may need at any time during the arrangement. A professional model of surrogacy acknowledges the fundamentally ethical nature of the act of giving birth to a child for someone else and recognizes the vulnerability of both the surrogate mother and the intended parents. It accords the women who choose to act as surrogate mothers the dignity enjoyed by other professionals whose need for payment is not assumed to reduce their generosity.

\section{Bibliography}

All about surrogacy.com (2016) 'Sample GS Contract', http://www.allaboutsurrogacy.com/sample contracts/GScontract1.htm

R. Almeling (2009) 'Gender and the Value of Bodily Goods: Commodification in Egg and Sperm Donation', Law and Contemporary Problems, 72(3): 37-58.

American College of Obstetricians and Gynecologists (1992) 'Ethical Issues in Surrogate Motherhood', International Journal of Gynecology and Obstetrics, 31: 139144.

\section{R. Badcock (1986) The Problem of Altruism. Oxford: Basil Blackwell}

British Medical Association (1996) Changing Conceptions of Motherhood: The Practice of Surrogacy in Britain. British Medical Association, London. 
C. Campanile (2015) 'Dad demands abortion after surrogate learns she's having triplets', New York Post, http://nypost.com/2015/11/25/surrogate-carrying-tripletssays-dad-demanding-she-abort-one/

J. Carbone \& J. L. Madeira (2015) 'The Role of Agency: Compensated Surrogacy and the Institutionalization of Assisted Reproduction Practices', Washington Law Review Online 90 (7).

D. Carr (1999) 'Professional Education and Professional Ethics', Journal of Applied Philosophy 16 (1): 33-46.

H. Choi et al. (2012) 'Decision Making Following a Prenatal Diagnosis of Down Syndrome: An Integrative Review', Journal of Midwifery and Women's Health 57(2): 156-164.

J. C. Ciccarelli \& L. J. Beckman (2005) 'Navigating Rough Waters: An Overview of Psychological Aspects of Surrogacy', Journal of Social Issues 61: 21-43.

ConceiveAbilities (2016a) 'Gestational Surrogate Program Fee Schedule - 2012', https://www.conceiveabilities.com/pdf forms/SurrogacyFee Schedule2012.pdf

ConceiveAbilities (2016b) 'Surrogacy Requirements', https://www.conceiveabilities.com/surrogates/surrogate-requirements

K. Conley \& C. Campanile (2015) 'Second surrogate mom steps forward with abortion battle', New York Post, http://nypost.com/2015/11/26/second-surrogatemom-steps-forward-with-abortion-battle/

A. J. Culyer (1973) 'Quids without Quos - A Praxeological Approach' in A. Alchian et al. (eds) The Economics of Charity: Essays on the Comparative Economics and Ethics of Giving and Selling, with Applications to Blood. London: Institute of Economic Affairs, pp. 33-61.

N. Davis (1988) 'Reproductive Technologies and our Attitudes towards Children', Logos, 9: 51-77.

K. Drabiak et al. (2007) 'Ethics, Law, and Commercial Surrogacy: A Call for Uniformity', Journal of Law, Medicine \& Ethics 35: 303-305.

K. Drabiak-Syed (2011) 'Waiving Informed Consent to Prenatal Screening and Diagnosis? Problems with Paradoxical Negotiation in Surrogacy Contracts', Journal of Law, Medicine \& Ethics, 39(3): 559-564.

R. Fischer (2011) 'Surrogacy', OHbaby! Magazine, 14.

http://www.ohbaby.co.nz/conception/surrogacy/ 
P. Gerber \& K. O'Byrne (2015) 'Souls in the House of Tomorrow: The Rights of Children Born via Surrogacy' in P. Gerber \& K. O'Byrne (eds) Surrogacy, Law and Human Rights. Burlington, Ashgate, pp. 81-112.

D. Koehn (1994) The Ground of Professional Ethics. London, Routledge.

P. Laufer-Ukeles (2013) 'Mothering for Money: Regulating Commercial Intimacy', Indiana Law Journal 88 (4).

J. Millbank (2015) 'Rethinking “Commercial” Surrogacy in Australia', Journal of Bioethical Inquiry, 12 (3): 477-490.

D. Mussen (2014) 'Surrogacy Payment Review Urged', The Dominion Post, August 18, 2014.

H. Ragoné (1994) Surrogate Motherhood: Conception in the Heart. Boulder: Westview Press.

S. Rudrappa \& C. Collins (2015) 'Altruistic Agencies and Compassionate Consumers: Moral Framing of Transnational Surrogacy', Gender \& Society, 29 (6): 937-959.

R.M. Shaw \& L.J. Bell (2014) “"Because you can't Live on Love": Living Kidney Donors' Perspectives on Compensation and Payment for Donation', Health Expectations. DOI: 10.1111/hex.12310.

C. Trenwith (2010) 'Surrogacy Payments “Difficult to Stop"', Brisbane Times, February 12, 2010.

O. van den Akker, (2003) 'Genetic and Gestational Surrogate Mothers' Experience of Surrogacy'. Journal of Reproductive and Infant Psychology 21 (2): 145-161.

W.N.K.A. van Mook et al. (2009) 'Professionalism: Evolution of the Concept', European Journal of Internal Medicine, 20: e82.

L. van Zyl \& R. Walker (2013) 'Beyond Altruistic and Commercial Contract Motherhood: The Professional Model', Bioethics, 27(7): 373-381.

R. Walker \& L. van Zyl (2015) 'Surrogate Motherhood and Abortion for Fetal Abnormality', Bioethics, 29 (8): 529-535.

R. Walker \& L. van Zyl (2016) 'Altruism and Generosity in Surrogate Motherhood'. Research in Ethical Issues in Organisations, 15: 121-133. 
C. Woulfe (2013) 'The Untold Story of NZ's Surrogate Babies', New Zealand Listener, 26 September, http://www.listener.co.nz/current-affairs/the-untold-story-of-nzssurrogate-babies/

\section{Acknowledgements}

The authors would like to thank Rhonda Shaw and an anonymous reviewer for helpful comments and suggestions on earlier drafts of this chapter.

\section{Notes}

' In New Zealand, for example, Section 14(3) of the Human Assisted Reproductive Technology Act (2004) prohibits commercial surrogacy, and states that it is an offence to give or receive 'valuable consideration' in exchange for participation in a surrogacy arrangement. The law does not allow for payment to cover the cost of time off work or to compensate the surrogate mother for inconvenience. There are significant penalties for any person who breaks the law.

ii See Woulfe, 2013; Mussen, 2014.

iii See Rudrappa \& Collins, 2015.

iv We discuss this point in Van Zyl \& Walker (2013).

$\checkmark$ See Trenwith, 2010; Woulfe, 2013.

vi See Panitch, 2013.

vii See Ciccarelli \& Beckman, 2005; Laufer-Ukeles, 2013; Ragoné, 1994.

viii See Drabiak et al., 2007; Almeling, 2009.

ix See, for instance, Campanile, 2015 and Conley \& Campanile, 2015.

${ }^{x}$ We discuss this issue in Walker \& Van Zyl (2015). See also Drabiak-Syed, 2011.

xi See also Van Zyl \& Walker, 2013; Millbank, 2015.

xii See Carbone \& Madeira, 2015.

xiii It will be noted that most members of these professions, and indeed all surrogate mothers, are women. The link between gender and exploitation in the caring professions raises a unique set of questions, some of which we discuss in forthcoming work. In this chapter we set aside these questions and instead focus on the compatibility of care and compensation in the professions. Caring is not gendered. There are men in each of these professions who provide exemplary care. xiv Compensation does preclude altruism, where altruism is defined as a selfless regard for others. As we argue elsewhere, altruism is not a morally desirable ideal (Walker \& Van Zyl, 2016).

${ }^{x v}$ Indeed, as Culyer (1973) notes in his discussion of blood donation, monetary benefits may induce altruistic behavior that would otherwise be constrained if the full cost were on the donor. 
xvi Shaw \& Bell (2014) make a similar point about living organ donation in NZ, especially with respect to prospective donors from low income families. 